\title{
Bazı Kavun Genotiplerinde Arbuscular Mikorhizal Fungus (AMF) Uygulamalarının Fusarium oxysporum f.sp. melonis'e Dayanıklılık Düzeylerine Etkileri*
}

\author{
Ayşe TORUN ${ }^{1}$, Önder TÜRKMEN ${ }^{1}$
}

ÖZET: Bu araştırma, Van Gölü Havzası'ndan selekte edilen ve Fusarium oxysporum f.sp. melonis'in 1 nolu ırkına (Fom) dayanıklılık düzeyleri belirlenmiş bazı yerel kavun genotiplerinde Arbüsküler Mikorizal Fungus (AMF) uygulamalarının Fom'un 1 nolu ırkına dayanıklılık düzeylerindeki değişimleri ortaya koymak amacıyla yürütülmüştür. Selçuk Üniversitesi Ziraat Fakültesi seraları ve laboratuvarlarında yürütülen bu araştırmada, bitki materyali olarak 65 MUR 01, 65 ERD 06, 65 EDR 03, 13 TAT 01, 65 MER 06 ve 65 EDR 02 kavun genotipleri, mikorizal fungus olarak Glomus intraradices (G. intraradices) ve Gigaspora margarita (G. margarita) türleri kullanılmıştır. Denemede 1:2:2 oranında dere kumu, bahçe toprağı ve çiftlik gübresinden oluşan yetiştirme ortamı kullanılmıştır. Deneme boyunca doğal olarak ortaya çıkabilecek mikorizal bağımlılık ve farklı toprak kaynaklı hastalık etmenlerinden sakınmak için yetiştirme ortamı sterilize edilmiş ve sulamalarda saf su kullanılmıştır. Üç tekerrürlü olarak yürütülen araştırmada, her parselde $250 \mathrm{ml}$ hacimli 15 saksı ve her saksıda bir bitki bulundurulmuştur. Tohum ekiminden 40 gün sonra deneme sonlandırılmış, her parselden 5 bitki fusarium testi için laboratuvara alınmış ve 30 gün süre ile gözlem altında tutulmuşlardır. Kontrol grubu parsellerde değişik oranlarda duyarlılık gösteren 65 MUR 01, 65 EDR 03, 13 TAT 01 ve 65 MER 06 genotiplerinin Fom 1 inokulasyonu yapılmış G. intraradices uygulamasında, hastalıktan hiç etkilenmedikleri görülmüştür. G. margarita'da ise 65 MUR 01, 65 ERD 06 ve 13 TAT 01 nolu genotiplerde yapılan testleme sonucu hastalık belirtisi gözlenmemiştir. Genel olarak $G$. intraradices mikoriza türü Fom'un 1 nolu ırkına dayanıklılık seviyesinin artmasında en iyi etkiye sahip olmuştur.

Anahtar Kelimeler: Fusarium oxysporum f.sp. melonis, Glomus intraradices, Gigaspora margarita, kavun

\section{Effects of Different Arbuscular Mycorrhizal Fungi Applications on Resistance Levels of Fusarium oxysporum f.sp. melonis in Some Melon Genotypes}

\begin{abstract}
The study was conducted to determine the effects of Arbuscular Mycorrhizal Fungus (AMF) applications on resistance levels of some selected from Van Lake Basin local melon genotypes that were predetermined resistant situations against to the Fom 1 race of Fusarium oxysporum f.sp. melonis . In study carried out at Selçuk University, Agricultural Faculty Experimental greenhouses and laboratories, 65 MUR 01, 65 ERD 06, 65 EDR 03, 13 TAT 01, 65MER 06 and 65 EDR 02 melon genotypes were used as plant material; Glomus intraradices (G. intraradices) and Gigaspora margarita (G. margarita) were used as mycorrhizal fungi. In experiment, the ratios of 1:2:2 sand, garden soil and farmyard manure were used as growth media. To protect the diseases associated from soils and naturally presence of mycorrhizal problems, growth media was irrigated with distilled water. The each plots had the 15 pots with a capacity of $250 \mathrm{ml}$ and there was only one plant in each pot. The experiment was ended after the 40 days from seed sowing. The five plants were taken from each plot for fusarium test and they were put on 30 days observation in laboratory. In the control plots, from various sensitive genotypes, 65 MUR 01, 65 EDR 03, 13 TAT 01 and 65 MER 06 numbered genotypes never became ill in the $G$. intraradices application. Moreover, 65 MUR 01, 65 ERD 06 and 13 TAT 01 numbered genotypes never became ill in the G. margarita applications. It was indicated $G$. intraradices mycorrhiza species had generallythe best effect in increasing level of tolerant to Fom 1 .
\end{abstract}

Key Words: Fusarium oxysporum f.sp. melonis, Glomus intraradices, Gigaspora margarita, melon

\footnotetext{
Ayşe TORUN (0000-0002-5983-0039), Önder TÜRKMEN (0000-0003-3218-6551), Selçuk Üniversitesi, Ziraat Fakültesi, Bahçe Bitkileri, Konya, Türkiye

Sorumlu yazar/Corresponding Author: Ayşe TORUN, aozer@selcuk.edu.tr
} 


\section{GíRiş}

Türkiye, Anadolu'dan Japonya'ya kadar uzanan kavunun ikincil gen merkezleri arasında yer almaktadır (Pitrat ve ark., 1999). Türkiye'de zengin yerel kavun popülasyonları olduğu değişik araştırmacılar tarafından belirtilmiştir (Günay 2005, Türkmen ve ark. 2005).

Kavun monoik veya andromonoik karakterlerde çiçek yapısına sahip olan ve bu çiçek yapısından dolayı yabancı döllenme özelliği gösteren bir sebzedir. Yabanc1 döllenmeden dolayı oluşan bu zengin genetik çeşitliliğin, Van Gölü Havzası kavun 1slahı ve seleksiyonunda verim, kalite ve olumsuz çevre koşullarına toleransı geliştirilebilecek seleksiyon ve 1slah programları için önemli bir gen kaynağı olabileceği belirtilmektedir (Türkmen ve ark. 2005).

Yetiştiricilikte bazı kültürel işlemlerin yanlış veya eksik uygulanması tüm bitkilerde olduğu gibi kavunda da hastalık ve zararlı probleminin artmasına ve büyük sıkıntıların yaşanmasına yol açmaktadır. Türkiye'deki kavun üretiminde karşılaşılan önemli sorunlardan birisi de Fusarium solgunluğudur. Toprak kökenli bir hastalık etmeni olan ve $0,1,2$ ve 1-2 olmak üzere 4 farklı 1rk1 olan Fusarium oxysporum f.sp. melonis, Türkiye'de ve dünyanın birçok kavun üretim bölgesinde yaygın bir şekilde görülmektedir (Baran 2000, Schreuder ve ark., . 2000, Kurt ve ark. 2002, Türkmen ve ark. 2005).

Fusarium solgunluğunun gelişiminde, çevre, bitki, patojen ve bitki-patojen etkileşiminin etkili olduğu bilinmektedir (Schreuder et al. 2000, Burger et al. 2003). Bu nedenle, kimyasal mücadelenin etkisiz, pratik ve ekonomik olmadığı bu toprak kökenli hastalık etmenine karşı dayanıklı çeşit kullanımı ön plana çıkmaktadır (Türkmen ve ark. 2005).

Yapılan sayısız araştırmada, AMF ile birlikte oluşan mikorizal infeksiyon bitkinin direncini artırdığ 1 için hastalık ve zararlıların etkisini azaltabileceği gibi şiddetini de düşürebileceği bildirilmiştir. Bitki kök bölgesinde veya dokularında mikorizal fungus ile patojen arasındaki ilişkide, kök salgılarının konsantrasyonu ve içeriğinde meydana gelen değişim patojenin etkisini zayıflattığı gibi aynı zamanda mikorizalı kök tarafından üretilen antibiyotik yanında patojenlere karşı koyacak yararlı mikroorganizmanın kök yüzeyinde oluşmasını fiziksel olarak patojenlerin köklere etki etmesini engellemektedir. Doğadaki birçok endemik patojenlerden Fusarium ve Pythium türlerine karşı mikorizal fungusun belirli biyokontrol ajanlarını devreye sokarak zararlıyı kontrol edebildiği bildirilmiştir (Ortaş ve ark. 2000). Bitki ile ilişkiye giren AMF mantarı, bitkiye penetrasyon yaptıktan sonra bitkide önemli fizyolojik değişikliklere yol açmakta ve bu durum bitkilerin hastalı etmenlerine karş1 davranışlarını da etkilemektedir (Schönbeck 1980).

Bazı durumlarda bir bitkinin bir zararlıya veya hastalığa gösterdiği görünürdeki direnç, beslenmedeki artışın bir sonucu olabilir (Cordier ve ark.,1996, Karagiannidis. 2002). AMF kolonizasyonu, bitkide patojen saldırısından önce meydana gelirse dayanıklılık mekanizması ortaya çıkacaktır (Slezack ve ark., 1999, Matsubara ve ark.,2001, Sylvia ve Chellemi 2001).

Fusarium solgunluğuna karşı çeşitli kimyasal mücadele yöntemlerinin etkinlikleri de denenmiş ancak kimyasal mücadelede uygulanan fungusitlerin etkili, pratik ve ekonomik olmaması nedeniyle hastalıkla mücadelede dayanıklı çeşit kullanımının öneminin daha da arttığ 1 ve bu nedenle etkili ve ekonomik bir mücadele yöntemi olduğu bildirilmiştir (Demir ve ark. 2006).

Araştırmada özellikle kavun yetiştirilen arazilerde en büyük sorunlardan birisi olan ve solgunluk hastalığ olarak bilinen toprak kökenli $F$. oxysporum f.sp. melonis mücadelesinde alternatif bir yöntem olabileceği düşünülen AMF uygulamalarının etkisi belirlenmeye çalışılmıştır. Bu amaçla, daha önce Türkmen ve ark.'nın (2005) Van Gölü Havzası'ndan selekte ettikleri ve $F$. oxysporum f.sp. melonis'e dayanıklılık düzeylerini belirledikleri bazı kavun genotiplerinin kullanıldığ araştırmada, AMF uygulamalarının $F$. oxysporum f.sp. melonis'e dayanıklılık seviyelerini olumlu yönde etkileyebileceği hipotezi test edilmeye çalışılmıştır.

\section{MATERYAL VE YÖNTEM}

Denemede bitkisel materyal olarak Türkmen ve ark. (2005)'nın Van Gölü havzasından selekte 65 MUR 01, 65 ERD 06, 65 EDR 03, 13 TAT 01, 65 MER 06 ve 65 EDR 02 kavun genotipleri kullanılmıştır. AMF uygulamaları Glomus intraradices, Gigaspora margarita ve kontrol şeklinde belirlenmiş olup bu AMF türleri Çukurova Üniversitesi, Ziraat Fakültesi Toprak Bölümü ve Fusarium izolatları YüzüncüYıl Üniversitesi Ziraat Fakültesi Bitki Koruma Bölümü'nden temin edilmiştir.

Araştırmada kullanılan fide yetiştirme harcını oluşturan toprak + dere kumu+ çiftlik gübresi karışımı deneme süresince oluşabilecek hastalıkları önlemek ve yetiştirme ortamında doğal olarak bulunabilecek mikorizalardan kaynaklanacak etkileri ortadan kaldırmak amacıyla $120{ }^{\circ} \mathrm{C}$ 'de 2 saat otoklav edilerek sterilize edilmiştir. Faktöriyel deneme desenine göre üç tekrarlamalı olarak yürütülen araştırmada, her tekrarda 
15 saksı bulundurulmuştur. Denemede $250 \mathrm{ml}$ hacimli plastik kaplara fide harcı yaklaşık $300 \mathrm{~g}$ doldurulduktan sonra tohum ekimi esnasında, 10 spor/g inokulum yoğunluğuna sahip ortamdan her saksiya tohum ekim derinliğine $4 \mathrm{~g}$ uygulanmıştır. Kontrol grubuna ise aynı özelliklere sahip mikorizasız ortama tohum ekimi yapılmıştır. Sulama suyundan kaynaklanacak herhangi bir bulaşmayı önlemek için deneme boyunca saf su kullanılmıştır. Denemede besin çözeltisi olarak N (300 ppm), P (200 ppm) ve K (200 ppm) uygulanmıştır.
Köklerde mikorizal infeksiyon teşhisi için, bitki köklerinin canlılığının korunması amacıyla bir kez çeşme suyunda, iki kez de saf suda yıkanmış olan bitki kökleri etil alkolde korunmaya alınmışlardır. Mikorizal infeksiyon için boyama işlemi Koske ve Gamma'ya (1989) göre yapılmıştır.

Köklerdeki AMF kolonizasyon yüzdesini saptamak üzere ise Grid-Line Intersect Metodu kullanılmış (Giovenetti and Mosse 1980) ve ilişkin model eşitlik 1 de verilmiştir.

\section{Infeksiyon Oranı $(\%)=\underline{\text { AMF ile kolonize olmus kök sayıs }} \times 100$ Toplam kök sayisl}

Dayanıklılık tespiti için hastalık inokulasyonu klasik hastalık bulaştırma yöntemiyle yapılmıştır. Kum kültürü adı da verilen bu metotla yapılan inokulasyonda mısır unu +kum kültürü kullanılmıştır (Turhan ve Grosman 1987). Bu yöntemde, otoklavda sterilize edilen 250 ml'lik cam şişeler içine $20 \mathrm{~g}$ mısır unu, $20 \mathrm{~g}$ agar ve $120 \mathrm{~g}$ steril yıkanmış dişli dere kumu konarak şişelerin içine $1 / 4$ oranında PDA' da geliştirilmiş 7-10 günlük $F$. oxysporum f.sp. melonis 1 nolu rrk kültürleri bırakılmıştır. Şişeler bir ay süre ile $25 \pm 2{ }^{\circ} \mathrm{C}$ 'de inkübe edilerek fungusun gelişimi sağlanmıştır

Gelişimi tamamlanan fungus kültürleri sterilize edilmiş 2:2:1 oranında bahçe toprağı, çiftlik gübresi, dişli dere kumu karışımından oluşan harç toprağına 19/1 oranında karıştırılarak 1000 ml'lik plastik kaplara konmuş ve AMF bulaştırılmış kavun fidelerinin ekimi yapılmıştır. Kontrol kaplarında ise mikorizal fungus inokule edilmemiştir. Plastik kaplar $25^{\circ} \mathrm{C}$ gündüz ve 16 ${ }^{\circ} \mathrm{C}$ gece sıcaklığında ve günlük ortalama 12 saat 1 şık alan laboratuarda 4 hafta boyunca tutularak hastalik gelişimi izlenmiştir.

Hastalık şiddeti değerlendirmesi 0-3 skalası kullanılarak yapılmıştır (Demir ve Tezcan 1995). Bu skalaya göre bitkilerdeki hastalık değerlendirmeleri aşağıda verildiği şekilde değerlendirmeye tabi tutulmuştur;

0: Hastalık semptomu yok

1: Kök boğazının 1/3'ünde hastalık lezyonu var

2: Kök boğazının 2/3'ünde hastalık lezyonu var

3: Bitki tamamen ölmüş

0-3 skalasına göre yapılan değerlendirme sonucunda kavun bitkilerinin aldıkları skala değerleri aşağıda eşitlik 2 de verilen formülde yerine konarak her bir genotip için hastalık şiddeti belirlenmiştir.

Hastalık şiddeti $(\%)=\left(\left(0 \times \mathrm{n}_{0}\right)+\left(1 \times \mathrm{n}_{1}\right)+\left(2 \times \mathrm{n}_{2}\right)\right.$ $\left.+\left(3 \times n_{3}\right)\right) \times 100 / \mathrm{n} \times 3$

Eşitlikte;

$\mathrm{n}_{0}$ : hastalık semptomu görülmeyen bitki sayıs1;

$\mathrm{n}_{1}$ : kök boğazının 1/3'ünde hastalık lezyonu olan bitki sayıs1;

$\mathrm{n}_{2}$ : kök boğazının 2/3'ünde hastalık lezyonu olan bitki sayısı;

$\mathrm{n}_{3}$ : tamamen ölmüş bitki sayısı;

n: toplam bitki sayısı;

3: kullanılan skaladaki en yüksek hastalık derecesi değeridir.

Genotiplerin hastalığa duyarlılık ve dayanıklılık seviyeleri ise genotiplerin hastalık yoğunluğu değerlerine göre belirlenmiştir. Kavun genotiplerinin dayanıklılık-duyarlılık seviyelerinin belirlenmesinde (1) dayanıklı (\%0-10) ve (2) duyarlı veya heterojen (\%10'un yukarısı) olmak üzere iki skala değeri kullanılmıştır.

Duyarlı bitkilerin bazen dış semptom oluşturmada gecikme göstermelerinden dolayı, genotiplerin duyarlılık seviyelerinin nihai tespitinde, kavun bitkilerinin kök boğazı gövde kesitlerinde vasküler dokudaki kahverengileşmeye de bakılmıştır (Karries ve ark., 2000, Wang ve ark.,2000).

Deneme tekniğine uygun olarak alınan tüm verilerin Mstad-c paket programında varyans analizleri yapılmıştır. İstatistik anlamda önemli çıkan ortalamalar Duncan çoklu karşılaştırma testine tabi tutulmuştur. 


\section{BULGULAR VE TARTIŞMA}

F. oxysporum f.sp. melonis in 1 nolu irkına karşı genotiplerin dayanıklılık düzeylerindeki değişimler
0-3 skalasına göre belirlenmiş, sonuçlar oransal olarak gösterilmiş ve varyans analizi yapılmamıştır. Elde edilen sonuçlar Çizelge 1' de özetlenmiştir.

Çizelge 1. Bazı yerel kavun genotiplerinin AMF uygulamalarında F. oxysporum f.sp. melonis 'in 1 nolu rrkına dayanıklılık şiddetine (\%) etkisi

\begin{tabular}{lccccccc}
\hline Mikoriza & 65MUR01 & 65ERD06 & 65EDR03 & 13TAT01 & 65MER06 & 65EDR02 & Ortalama \\
\hline AMF (-) & 67 & 52 & 48 & 48 & 22 & 15 & 42 \\
AMF(Gi) & 0 & 4 & 0 & 0 & 0 & 4 & 1 \\
AMF(Gm & 0 & 0 & 15 & 0 & 4 & 11 & 5 \\
Ortalama & 22 & 19 & 21 & 16 & 9 & 10 & \\
\hline
\end{tabular}

Araştırmada kullanılan kavun genotiplerinde AMF uygulanmayan parsellerde ortalama $\% 42, G$. intraradices'de $\% 1$, G. margarita' da ise $\% 5$ oranında bitkilerin hastalandıkları tespit edilmiştir. Genel olarak AMF uygulamaları hastalık şiddetini önemli düzeylerde azaltmış olup, G. intraradices, G. margarita'dan daha etkili bulunmuştur. F. oxysporum f.sp. melonis' in 1 nolu ırkına ait izolatla yapılan testlemede duyarlılık düzeyleri AMF uygulanmayan parsellerde $\% 67$ ile $\% 15$ arasinda değişmiştir. $G$. intraradices uygulanmış parsellerde yapılan testlemelerde ise genotiplerin hastalanma oranları $\% 0$ ile \% 4 arasında değişmiş, G. margarita'da ise bu oran $\% 0$ ile $\% 15$ aralığında saptanmıştır (Çizelge 1).
F. oxysporum f.sp. melonis'in 1 nolu irkına karş1 genotiplerin duyarlılıklarında en dikkat çekici sonucu 65 MUR 01 nolu genotip vermiştir (Çizelge 1 ve Şekil 1). Bu genotipte AMF'nin kontrol parsellerinde \% 67 oranında hastalanma gözlenirken, $G$. intraradices ve $G$. margarita' da bu oran $\% 0$ olarak tespit edilmiştir. Kontrol parsellerinde $F$. oxysporum f.sp. melonis' in 1 nolu irkına ait izolatla karşı değişik oranlarda duyarlılık gösteren 65 MUR 01, 65 EDR 03, 13 TAT 03 ve 65 MER 06 nolu genotiplerin duyarlılıkları G. intraradices uygulamas1 ile \% 0'a inmiştir. G. margarita uygulamasında ise \% 100 dayanıklı bulunan genotipler 65 MUR 01, 65 ERD 06 ve 13 TAT 01 olmuştur (Çizelge 1).

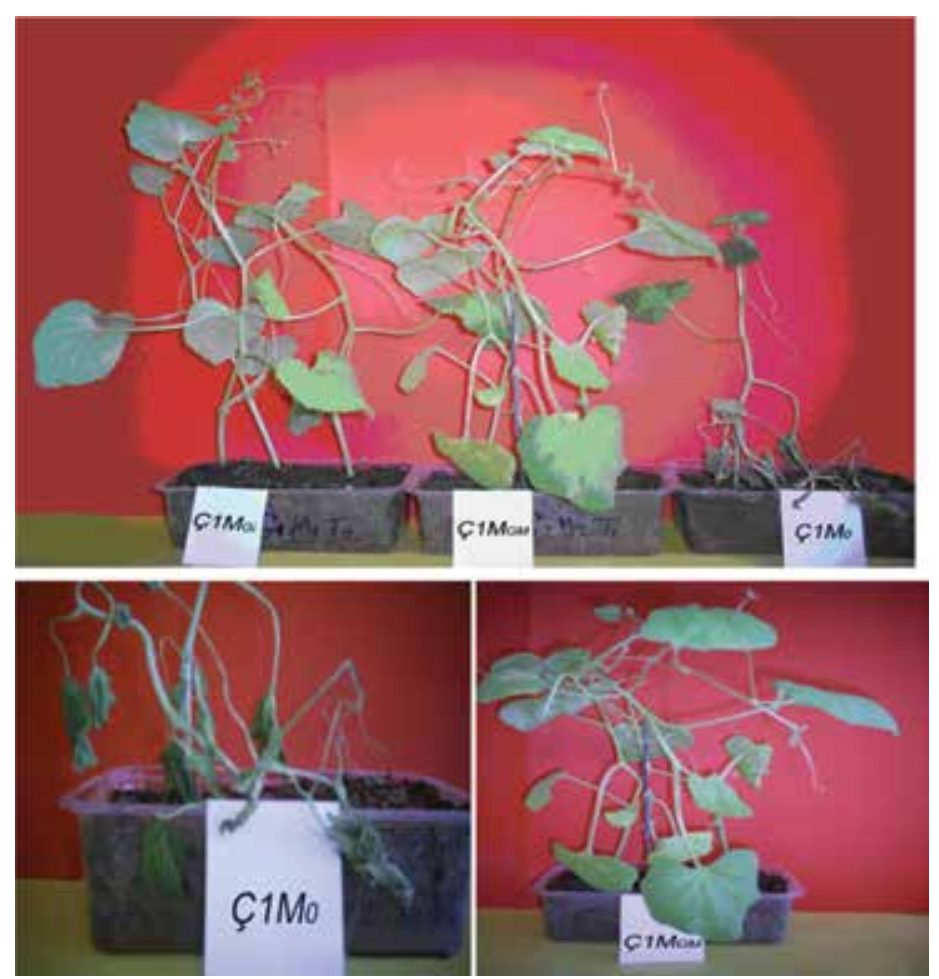

Şekil 1. 65 MUR 01 genotipine AMF uygulamalarının F. oxysporum f.sp. melonis' in 1 nolu irkına etkisi 
Araştırmamızda kavun genotiplerinde $F$. oxysporum f.sp. melonis' in 1 nolu 1 rkının hastalı şiddetinin azalmasında AMF uygulamalarının, önemli oranlarda etkisinin olduğu saptanmıştır. Nitekim kontrol grubu parsellerde ortalama hastalanma oran1 \% 42 olarak hesaplanırken, $G$. intraradices uygulanan parsellerde bu oran $\% 1$ e, G. margarita uygulanan parsellerde ise $\% 5$ 'e düşmüştür. Kontrol grubu parsellerde değişik oranlarda duyarlılık gösteren 65 MUR 01, 65 EDR 03, 13 TAT 01 ve 65 MER 06 genotiplerin hastalık inokülasyonu ile birlikte $G$. intraradices uygulamasında hastalıktan hiç etkilenmedikleri görülmüştür. Aynı zamanda G. margarita'da 65 MUR 01, 65 ERD 06 ve 13 TAT 01 nolu genotiplerde yapılan hastalık testlemesi sonucunda hastalık belirtisi gözlenmemiştir. Akköprü (2004) domateste yürüttüğü benzer çalışmada AMF uygulamalarının toprak kaynaklı patojenlerin kontrolünde etkili olabileceğini bildirmiştir. Ayrıca Yeşilova (2005) kavunda $F$. oxyporium f.sp. melonis 'in kontrolünde AMF uygulamalarının kullanılabileceğini bildirmiştir. Ancak burada kullanılan iki AMF irk1 arasında hastalık şiddeti açısından önemli farklılıklar görülmüştür. Pek çok araştırma AMF uygulamalarında yüksek başarı için konukçu konuk ilişkisinin çok önemli olduğunu vurgulamaktadır (Türkmen ve ark. 2008, Vicari ve ark., 2002, Waceke ve ark., 2002). Bu hipotez bizim araştırmamızda kavun genotipleri ile AMF ırkları interaksiyonunda da net olarak görülmektedir.

Çizelge 2. Bazı yerel kavun genotiplerinde AMF uygulamalarının köklerdeki kolonizasyon oranları (\%)

\begin{tabular}{lccccccc}
\hline Mikoriza & 65MUR01 & 65ERD06 & 65EDR03 & 13TAT01 & 65MER06 & 65EDR02 & Ortalama \\
\hline AMF (-) & 20 & 20 & 0 & 20 & 0 & 10 & 12 \\
AMF(Gi) & 90 & 70 & 70 & 80 & 70 & 50 & 72 \\
AMF(Gm & 80 & 90 & 30 & 80 & 60 & 40 & 63 \\
Ortalama & 63 & 60 & 33 & 60 & 43 & 33 & \\
\hline
\end{tabular}

Mikorizal bağımlılıkta en önemli parametrelerden birisi olarak kabul edilen kök kolonizasyonun da fide yetiştirme ortamını sterilize etmemize rağmen kontrol grubu parsellerde \% 12 oranında kök kolonizasyonu gerçekleşmiştir. G. intraradices' de ortalama \% 72, G. margarita da \% 63 kolonizasyon görülmüş olup, genel olarak kavunda yüksek bir kolonizasyon oranına ulaşılmıştır (Çizelge 2). Buna göre kolonizasyon oranlarının genotiplere ve AMF türlerine göre değişkenlik gösterdiği belirlenmiştir. Onoğur ve Demir (1998), Ortaş ve ark. (2000), Matsubara ve ark., (1995), Caron ve ark., da (1985) yaptıkları araştırmalarında kolonizasyon yoğunluğunun AMF ırklarına göre değiştiğini bildirmişlerdir.

\section{KAYNAKLAR}

Akköprü A, 2004. Arbusküler Mikorizal Fungus (AMF) Glomus intraradices ve Bazı Kök Bakterilerinin (KB) Domateste Fusarium Solgunluğuna ( Fusarium oxysporum f.sp. lycopersici) (Sacc) Synd. Et (Hans) ve Bitki Gelişme Parametrelerine Etkisi. Yüzüncü Y1l Üniversitesi, Fen Bilimleri Enstitüsü, Yüksek Lisans Tezi, 88s.

Baran B, 2000. Güneydoğu Anadolu Bölgesi Kavun Ekim Alanlarında Solgunluk Hastalığı Etmeni "Fusarium

\section{SONUÇ}

Sonuç olarak bu çalışmada kavunda bitki gelişimi üzerine AMF uygulamaların etkisi net olarak ortaya konmuş olup, G. margarita G. intraradices'ten daha üstün bir performans sergilemiştir. Diğer taraftan kullanılan kavun genotiplerinde genotiplere göre değişmekle birlikte $F$. oxysporum f.sp. melonis' in 1 nolu ırkından etkilenmesini azaltmıştır.

Dayanıklılık testleri üzerinde G. intraradices'in başarısı öne çıkmış olmasına rağmen, G. margarita'nın da hastalık şiddeti üzerine etkisi dikkate alındığında her iki AMF türünün de bu amaçla kullanılabileceği düşünülmektedir.

oxysporum f.sp. melonis'in (Leach and Currence)" Yaygınlığ ve $\mathrm{Bu}$ Etmene Karşı Bazı Kavun Çeşitlerinin Tepkileri. Yüksek Lisans Tezi. Yüzüncü Yıl Üniversitesi, Fen Bilimleri Enstitüsü, 29s.

Burger Y, Katzir N, Tzuri G, Portnoy V, Saar U, Shriber S, PerlTreves R, Cohen R, 2003. Variation in the Response of Melon Genotypes to Fusarium oxysporum f.sp. melonis Race 1. Determined by Inoculation Tests and Molecular Markers. Plant Pathology 52:204-211. 
Caron M, Fortin JA, Richard C, 1985. Influence of Substrate on the Interactions of Glomus intraradices and Fusarium oxysporum f.sp. radicis lycopersici on Tomatoes. Plant and Soil 87: 233 $-236$.

Cordier C, Trouvelot A, Gianinazzi S, Gianinazzi-Pearson V, 1996. Arbuscular Mycorrhiza Technology Applied to Micropropagated Prunus avium and to Protection Against Phytoplhora cinnamomi. Agronomie 16, 679-688.

Demir S, Tezcan H, 1995. Van İli Kavunlarında Toprak Kaynaklı Fungusların Neden Olduğu Kurumalar Üzerinde Araştırmalar. VII. Türkiye Fitopatoloji Kongresi Adana, 26-29 Eylül, 204207.

Demir S, Türkmen Ö, Şensoy S, Akkökprü A, Erdinc C, Yildiz M, Kabay T, 2006. Reactions of Melon Landraces Grown in the Lake Van Basin to the Physiologic Races of Fusarium oxysporum f.sp. melonis. European Journal of Horticultural Science, 71(2).s.91-95.

Giovanetti M, Mosse B, 1980. An Evaluation of Techniques for Measuring VAM Infection in Roots. New Phytol. 84: 489-500.

Günay A, 2005. Özel Sebze Yetiştiriciliği Cilt V. Ankara Üniversitesi, Ziraat Fakültesi, Ankara

Karagiannidis N, Bletsos F, Stavropoulos N, 2002. Effect of Verticillium Wilt (Verticillium dahliae Kleb.) and Mycorrhiza (Glomus mosseae) on Root Colonization, Growth and Nutrient Uptake in Tomato and Eggplant Seedlings. Sci. Honic 94, 145-156.

Karries T, Dean R, Thomas C, 2000. Toward the Development of Molecular Markers Linked to Race 2 Fusarium Wilt Resistance in Melon (Cucumis melo L.). Proc. Cucurbitaceae 2000. (Eds. N. Katzir \& H.S. Paris.) Acta Hort. 510:415-419.

Koske RE, Gamma JE, 1989. A Modified Procedure for Staining Roots to Detect VAM. Mycological Research 92, 486-505.

Kurt S, Baran B, Sarı N, Yetişir H, 2002. Physiologic Races of Fusarium oxysporum f.sp. melonis in the Southeastern Anatolia Region of Turkey and Varietal Reactions to Races of the Pathogen. Phytoparasitica 30(4):395-402.

Matsubara Y, Tamura H, Harada T, 1995. Growth Enhancement and Verticillium Wilt Control by Vesicular - Arbuscular Mycorrhizal Fungus İnoculation in Eggplant. J. Japan Soc. Hort. Sci. 64(3): 555 - 561

Matsubara Y, Ohba N, Fukui H, 2001. Effect of Arbuscular Mycorrhizal Fungus Infection on the Incidence of Fusarium Root Rot in Asparagus Seedlings. J. Jpn. Soc. Hoiic. Sci. 70, 202-206.

Onoğur E, Demir S, 1998. Bazı Kültür Bitkilerinde VesikülerArbusküler Mikorhiza (VAM) Oluşumu ve Bunun Bitki Gelişimi ve Dayanıklılıktaki Rolü Üzerinde Araştırmalar. TUBITAK. Tarım ve Ormancilık Grubu. Proje No: TOGTAG-1506.
Ortaş İ, Kaya Z, Sarı N, Gök M, Çakmak İ, Almaca A, Ergün B, Ortakçı D, Ercan S, Bolat H, 2000. Doğal Bir Gübre Olan Mikoriza Uygulamasının Bitkisel Verim ve Mineral Gübre Tasarrufundaki Rolü ve Mikorizaya Bağımlılık Duyan Kültür Bitkilerinin Seleksiyonu. DPT Proje No: 96K 120-580.

Pitrat M., Chauvet M, Foury C, 1999. Diversty, History and Production of Cultivated Cucurbits. Proc. 1st Int. Symp. on Cucurbits (Eds.K.Abak\&S.Büyükalaca) Acta Hort. 492:2128.

Schönbeck F, 1980. Endomycorrhiza in Relation to Plant Diseases Soil-Borne Plant Pathogens, Edited by B. Schippers and W. Gams., Acedemic Press, New York, 23, P:271-280.

Schreuder W, Lamprecht SC, Holz G, 2000. Race Determination and Vegetative Compatibility Grouping of Fusarium oxysporum f.sp. melonis from South Africa. Plant Disease 84(3):231-234.

Slezack S, Dumas-Gaudot E, Rosendahl S, Kjoller R, Paynot M, Negrel J, Gianinazzi S, 1999. Endoproteolytic Activities in Pea Roots Inoculated With the Arbuscular Mycorrhizal Fungus Glomus mosseae and/or Aphanomyces euieichcs in Relation to Bioproteuion. New Phytol. 142, 517-529.

Sylvia DM, Chellemi DO, 2001. Interactions Among RootInhabiting Fungi and Their Implications for Biological Control of Root Pathogens. Adv. Agron 73: 1-33.

Turhan G, Grossman F, 1987. Antagonistic Activity of N. vasinfecta var. africans (Von Arx.) Cannon and Hawkworth Against Soilborne Fungi, J. Phytopath. 123:199-206.

Türkmen Ö, Şensoy S, Demir S, Erdinç C, 2008. Effect of Two Different AMF Species On Growth and Nutrient Content of Pepper Seedlings Grown Under Moderate Salt Stres. African Journal of Biotocnology 7(4):394-396.

Türkmen Ö, Şensoy S, Demir S, Yıldız M, 2005. Van Gölü Havzası'nda Yerel Kavun Popülasyonlarının Islahı ve Seçilen Tiplerin Ticari Çeşitlerle Karşılaştırılması. TÜBITAKTOGTAK 2681

Vicari M, Hatcher PE, Ayres PO, 2002. Combined Effect of Foliar and Mycorrhizal Endophytes on an Insect Herbivore. Ecology $83,2452-2464$

Waceke JW, Waudo SW, Sikora R, 2002. Effect of Inorganic Phosphatic Fertilizers on the Efficacy of an Arbuscular Mycorrhiza Fungus Against a Root-Knot Nemalode on Pyrethram. Im. J. Pest Manage 48, 307-313.

Wang YH, Thomas CE, Dean RA, 2000. Genetic Mapping of a Fusarium Wilt Resistance Gene (Fom-2) in Melon (Cucumis melo L.). Mol Breed 6:379-389.

Yeşilova Ö, 2005. Kavunlarda VAM Uygulamasının Bitki Gelişimi ve Fusarium Solgunluğu Üzerindeki Etkilerinin Belirlenmesi. Süleyman Demirel Üniversitesi, Fen Bilimleri Enstitüsü, Bitki Koruma Anabilim Dalı, Yüksek Lisans Tezi, 50s. 